\title{
The blind leading the sighted
}

\section{An eye-opening experience of the wonders of perception.}

\section{$\mathrm{O}$}

Richard Gregory ne of the most dramatic, though very rare, human experiences is the acquisition of sight as an adult following blindness from birth. This happened to Sidney Bradford at the age of 52, having been recorded as blind at ten months and almost certainly blind, owing to an infection, from birth. Studying Bradford's new vision, and how it developed over the few years remaining to him, was the turning point at least for my appreciation of the wonders of perception.

It was my research assistant, Jean Wallace, who saw in a local paper in 1959 that a man, blind from birth and now 52, was about to receive new eyes - or rather, corneal grafts that might allow him to see. We gathered up every visual trick and gadget we thought might be relevant from the practical class we ran in the Cambridge Psychological Laboratory. Dropping teaching and other commitments, we drove to a Midlands hospital in time to see Bradford just after his first eye was opened to the light.

We found a cheerful, confident, middleaged man who was willing to be investigated and who, so far as we could tell then or later, was truthful and honest. But an initial shock nearly made us turn back with the disappointment that this must be a put-up job, or at least a Great Mistake: he correctly read the time on the clock in the ward. Could he have guessed it? Borrowing a nurse's alarm clock, we set its hands to various positions, and he told us the times it showed. Taking a large watch, which had no glass, from the top pocket of his jacket, he told its time by rapidly touching its hands, as he had done for many years. So he could see immediately, from earlier touch experience. At least for us, this was a turning point for understanding vision.

Also rather by accident, we found he could read the name of the popular Everybody's magazine, guessing the title from its upper-case letters even though he could not read the lower-case ones. It turned out that at the blind school he had attended, the boys were taught to read upper-case letters by touch, from wooden blocks engraved for the purpose. Technically, Bradford showed cross-modal transfer from touch to vision, which no one knew about at that time, although it was soon discovered by other researchers studying primates.

The classical reference for considering the possibilities of adult sight given infant blindness is John Locke's An Essay Concerning Human Understanding (1690). Locke quotes a letter from his friend William Molyneux, posing the question: "Suppose a man born

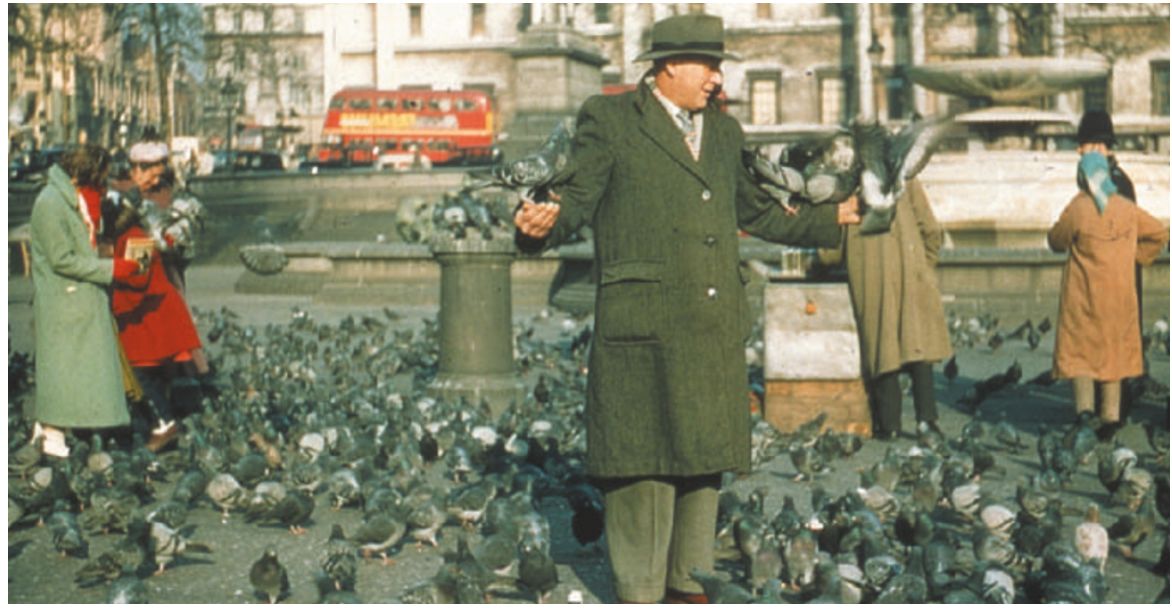

Common senses: as Sidney Bradford embraces sight, his experience of touch informs his new faculty.

blind, and now adult, and taught by his touch to distinguish between a cube and a sphere... [Then suppose] the blind man be made to see: query, whether by his sight, before he touched them, could he distinguish and tell which was the globe and which the sphere? To which the acute and judicious proposer answers, 'Not. For, though he has obtained the experience of how a globe, how a cube, affects his touch, yet he has not yet obtained the experience, that what affects his touch so or so, must affect his sight so or so." The philosopher George Berkeley (1685-1753) held the same opinion. And so, essentially, did psychologists at the time Bradford gained his vision, notably Donald Hebb. This distinguished Canadian psychologist, author of The Organization of Behaviour (1949), coined the idea of neural nets and believed sight to be a skill acquired only gradually.

Early cases of operable blindness (reviewed by Marius von Senden in 1932) involved lens cataracts, sight being given by removal of the lens. But as these primitive operations did not allow a decent retinal image for weeks or months, patients' slowness to see was interpreted as evidence that they had no initial vision. It is now known that babies a few hours beyond birth take interest in faces. Their responses to stimuli important to survival, such as facial expressions, suggest considerable immediate vision, as Bradford had. But Hebb was right that visual learning is important and slow it was only knowledge acquired from touch that enabled Bradford to interpret an artificial stimulus, such as a clock face, correctly.

Bradford's responses to well-known illusion figures were far from normal. He perceived far less distortion, and he did not experience the flipping ambiguity of the Necker Cube, or other such dynamic changes of appearance. Pictures looked flat and meaningless. Perspective meant nothing to his visual system, yet he could judge the distances and sizes of objects that were already familiar from touch, such as chairs scattered around the ward - although he was wildly wrong about distances to the ground from the hospital windows. Evidently, earlier touch experience and behaviour such as walking, calibrated and gave sense to his vision, which was almost useless for untouchable objects or pictures. His unusual responses to the figures suggested that many illusions result from cognitive processing, rather than physiological signal processing occurring early in the visual system; this led to experiments and interesting controversies that persist today.

Vision was generally thought to be separate from the other senses, and is still mainly studied in isolation; yet Bradford showed that exploratory touch - as well no doubt as taste, sound and other sensory experiences - gives richness and meaning to retinal images. For optical images are but ghosts, materialized into objects by perceptual experience of the non-visual properties of things.

Now there is a new case. Mike May, in California, lost sight in both eyes from a chemical accident when he was three-and-a-half years old. He regained sight by a corneal graft, but the unique operation required the use of stem cells, which is why this was delayed until 2000, when he was in his early forties. May's first visual experiences, and his currently developing vision, mirror those of Bradford's late entry to the world of sight. And what is happening in his brain can now be investigated, thanks to another miraculous turning point: the advent of brain imaging technologies.

Richard Gregory is in the Department of Experimental Psychology, University of Bristol, Bristol BS8 1TN, UK. 